\title{
Primary Open Angle Glaucoma
}

National Cancer Institute

\section{Source}

National Cancer Institute. Primary Open Angle Glaucoma. NCI Thesaurus. Code C35394.

A form of glaucoma in which there is no visible abnormality in the trabecular meshwork. 